This is a self-archived version of an original article. This version may differ from the original in pagination and typographic details.

Author(s): Kauhanen, Antti; Maliranta, Mika

Title: The roles of job and worker restructuring in aggregate wage growth dynamics

Year: 2019

Version: Accepted version (Final draft)

Copyright: (c) 2017 International Association for Research in Income and Wealth.

Rights: In Copyright

Rights url: http://rightsstatements.org/page//nC/1.0/?language=en

Please cite the original version:

Kauhanen, A., \& Maliranta, M. (2019). The roles of job and worker restructuring in aggregate wage growth dynamics. Review of Income and Wealth, 65(1), 99-118.

https://doi.org/10.1111/roiw.12315 


\section{THE ROLES OF JOB AND WORKER RESTRUCTURING IN AGGREGATE WAGE GROWTH DYNAMICS ${ }^{1}$}

Antti Kauhanen*

The Research Institute of the Finnish Economy ETLA

Mika Maliranta

The Research Institute of the Finnish Economy ETLA, and University of Jyväskylä

*Correspondence to: Antti Kauhanen, Research Institute of the Finnish Economy ETLA, (Lonnrotinkatu 4B, 00120 Helsinki, Finland) (antti.kauhanen@etla.fi)

Abstract

We propose an approach for measuring and analyzing the dynamics of the standard aggregate wage growth of macro statistics with micro data. Our method decomposes the aggregate wage growth into the wage growth of job stayers and into various terms related to job and worker restructuring. This method produces explicit expressions with clear interpretations for the various restructuring components. Using comprehensive longitudinal employer-employee data, we study how job and worker restructuring influence the aggregate wage growth and its cyclicality. The results highlight the importance of drawing a sharp distinction between job and worker restructuring in the analysis of aggregate wage growth dynamics.

Key words: Index theory, statistical decomposition, linked employer-employee data, restructuring, business cycles

JEL Codes: C43, E24, J3

${ }^{1}$ This study was supported by the Finnish Work Environment Fund (project 110309). We thank Juha Kilponen, Juuso Vanhala, and the participants in the 11th Comparative Analysis of Enterprise Data and COST Conference 2012 (Nuremberg, 2012) at the XXXIV Annual Meeting of the Finnish Economic Association (Vaasa, 2012), in the Summer Seminars of Finnish Economists (Jyväskylä, 2012), and in the SOLE Annual Meeting (Boston, 2013) for their comments. 


\section{Introduction}

Job restructuring is an important channel through which aggregate productivity growth, and hence economic growth, takes place. This channel includes the entry of new jobs, the exit of existing jobs, and the reallocation of resources between continuing jobs. Schumpeterian growth models emphasize the reallocation of resources between firms (Acemoglu et al., 2013,Lentz and Mortensen, 2008,Klette and Kortum, 2004,Aghion, Akcigit and Howitt, 2014), and empirical productivity studies have shown the quantitative importance of job restructuring on productivity growth (Foster, Haltiwanger and Krizan, 2001,Foster, Haltiwanger and Krizan, 2006,Baily, Bartelsman and Haltiwanger, 2001).

Although productivity and wages are closely connected to each other, the literature on aggregate wage growth dynamics has paid little attention to the role of job restructuring. Instead, the wage growth literature has mainly focused on the role of worker restructuring in the cyclicality of aggregate wages. This line of research has shown that although the wages of job stayers are mildly procyclical, aggregate wages are typically acyclical due to the countercyclical effect of compositional changes in worker structures over the business cycle (e.g. Bils, 1985,Solon, Barsky and Parker, 1994,Shin, 1994,Shin and Solon, 2007,Devereux, 2001).

However, the standard interpretation of these results has recently been challenged on the grounds that the role of job restructuring has been ignored (Gertler and Trigari, 2009,Martins, Solon and Thomas, 2012). Wages of individuals may fluctuate cyclically if the jobs that they hold vary cyclically; this would be the case even if wages in all jobs were rigid. Carneiro, Guimares and Portugal, (2012) found evidence suggesting that job composition has a countercyclical effect, i.e., low-paying jobs are destroyed in recessions. Gertler and Trigari, (2009) on the other hand found that job composition has a procyclical effect.

These micro-level studies have indicated the importance of both worker and job restructuring for assessing the cyclicality of wages of individuals. However, they have not considered how these compositional changes affect the aggregate wage series. As emphasized by Blundell, Reed and Stoker, (2003), aggregate wage growth is often used in policy discussions as a measure of change in the wellbeing of workers, but composition biases make this interpretation untenable. The relationship between individual wages, aggregate wages, 
and worker composition bias has been studied by Daly, Hobjin and Wiles, (2011) and Blundell, Reed and Stoker, (2003). These studies show that accounting for worker restructuring is important for the interpretation of aggregate wage movements. These studies have not, however, considered the role of job restructuring.

Despite the importance of job and worker restructuring in economic development in both the short run and the long run, our knowledge is insufficient with regard to their effects on aggregate wages. This shortfall is due to a lack of suitable tools for considering both types of restructuring simultaneously. We propose an approach for filling this gap. We present a novel decomposition that allows one to quantify the effects of job and worker restructuring on aggregate wage growth with longitudinal employer-employee data that contain information on wages and occupations. Our decomposition is related to the popular decompositions in the literature on aggregate productivity dynamics (e.g. Foster, Haltiwanger and Krizan, 2001,Griliches and Regev, 1995) but has a better index-theoretic foundation and the components have a clearer economic interpretation.

Our starting point, which is also the point of departure from the current literature, is that we measure the growth rate of average wages (i.e., the standard aggregate growth rate) separately from the average wage growth rate of job stayers. The difference between these two measures quantifies restructuring, which can be decomposed into job and worker restructuring, i.e. the changing composition of jobs and workers in the labor market. Clearly, these two restructuring components are inherently linked. Our approach to disentangling these mechanisms is to identify worker restructuring as changing worker composition within continuing jobs (through hirings and separations). This means that worker restructuring takes place only within fixed job structures.

Examining fixed job structures has two advantages. First, because job stayers can be found only in continuing jobs (i.e., in fixed job structures), our approach conveniently encompasses the analysis of wage changes among those who have retained their job match (i.e., job stayers). Second, when the fixed parts of job structures have been identified and their effects on wage growth have been measured, the results concerning the contribution of changing job structures to aggregate wage growth are easy to interpret. Here our decomposition uses similar logic to Maliranta, (2005), Böckerman and Maliranta, (2007), Diewert and Fox, (2009) and Melitz and Polanec, (2015), who study the micro-level 
components of aggregate productivity growth. Thus, our approach links wage analysis to the recent literature that emphasizes the role of creative destruction in economic growth.

Our decomposition can be made in two steps. In the first step, aggregate wage growth is decomposed into wage growth within jobs and job restructuring, and these factors are represented by 1) changing input (hours worked) shares between continuing jobs, 2) entries of jobs, and 3) exit of jobs. In the second step, we apply the decomposition formula once more but at a lower level of aggregation for each of the continuing jobs. This procedure allows us to split the within component of the jobs into four worker-level sources (within, between, entry, and exit). In addition, the decomposition involves a set of cross-term components that renders the decomposition consistent. Although these components are worthy of interest for the purpose of interpretation, empirically their importance is limited.

We apply our methodology to comprehensive longitudinal employer-employee data from the Finnish manufacturing sector that cover the drastic boom-bust-boom-bust cycles between the years 1985 and 2010. Our main findings fall into three main categories. The first category relates to the difference between aggregate wage growth and the wage growth of job stayers. We find that, on average, the wages of job stayers increase more rapidly than aggregate wages. Thus, job and worker restructuring have a combined negative effect on aggregate wage growth. This result is similar to the results of Daly, Hobjin and Wiles, (2011) and Blundell, Reed and Stoker, (2003) in that labor market restructuring drives a wedge between aggregate wage growth and the wage growth of individuals.

The second category concerns the effects of job restructuring (i.e., changing job composition) and worker restructuring (i.e. changing worker composition) on aggregate wage growth. We show the novel result that job restructuring and worker restructuring have opposite effects on aggregate wage growth. Job restructuring has a positive contribution to aggregate wage growth in the long run because the labor input share of high-wage jobs (i.e., occupations and firms that have a high level of wages) increases steadily over time via the exit of low-wage units and the expansion of high-wage units in terms of hours worked. This pattern can be interpreted as productivity-enhancing restructuring at the level of jobs. Worker restructuring on the other hand contributes negatively to aggregate wage growth because highly paid older workers retire and low-paid younger workers enter the labor markets. Of these two restructuring components, the worker-restructuring component is dominant, and thus restructuring has a negative contribution to the aggregate wage growth. 
The third set of results concerns the role of job and worker restructuring in the cyclical variation of aggregate wages. We find that aggregate wage growth is much less procyclical than the wage growth of job stayers because both job and worker composition have a strongly countercyclical effect on aggregate wage growth. Our results explicitly determine the magnitudes and cyclical sensitivity of the job- and worker-restructuring components of aggregate wage growth. The earlier literature has only considered worker restructuring.

\section{Related Literature}

Our paper is related to several strands of the literature. In particular, this paper has direct links to the literature on micro-level sources of aggregate productivity growth, which utilizes various (shift-share type) methods for decomposing aggregate productivity growth into components by gauging the contributions of entries, exits, and reallocations between continuing firms (or plants) in conjunction with the productivity growth of continuing firms (see e.g. Baily, Hulten and Campbell, 1992,Baily, Bartelsman and Haltiwanger, 2001,Foster, Haltiwanger and Krizan, 2001,Foster, Haltiwanger and Krizan, 2006,Foster, Haltiwanger and Syverson, 2008,Melitz and Polanec, 2015). These analyses illustrate the importance of analyzing aggregate productivity growth in the context of a heterogeneous firm framework. For excellent reviews of this literature, see Bartelsman and Doms, (2000) and Syverson, (2011). Although our paper is similar in substance, it applies these ideas to aggregate wages, and certain methodological extensions are needed for our current purposes (see Sections 3 and 4). In addition, firm dynamics and productivity-enhancing reallocations of resources have central positions in the recent literature on international trade, FDI, and geography (e.g. Melitz, 2003,Helpman, Melitz and Yeaple, 2004,Helpman, 2006,Baldwin and Okubo, 2006).

Our approach is most strongly connected to the large body of literature that examines how the movement of aggregate wages is linked to the cyclicality of labor market dynamics. This literature has shown that that the quality of the workforce (as measured by earnings) varies over the business cycle because of the changing worker composition, which leads to a smoother cyclical behavior pattern for aggregate wages (e.g. Bils, 1985,Solon, Barsky and Parker, 1994,Shin, 1994,Shin and Solon, 2007,Devereux, 2001). This literature has also shown that the wages of job changers are more cyclical than those of job stayers (e.g. Solon, Barsky and Parker, 1994,Barlevy, 2001,Devereux, 2001,Devereux and Hart, 2006,Shin, 1994,Carneiro, Guimares and Portugal, 2012,Martins, Solon and Thomas, 2012). 
The role of job composition has received less attention. Cyclical movements between jobs may affect aggregate wages even if the wages are rigid in each job and there are no changes in worker composition (i.e., changes such that the same employees are working in different jobs). In this case, the acyclicality of aggregate wages stems solely from job restructuring in the economy (that is, the creation and destruction of jobs with varying productivity). Carneiro, Guimares and Portugal, (2012) showed that adding job title dummies to wage regressions increases the sensitivity of wages of both job stayers and new hires to the unemployment rate, suggesting that job composition has a countercyclical effect. Gertler and Trigari, (2009) on the other hand found that once they control for match-specific fixed effects, the wages of new hires are not more cyclical than the wages of job stayers. Their interpretation is that job composition has a procyclical effect. Solon, Whatley and Stevens, (1997) and Devereux and Hart, (2006) showed that movements between positions are cyclical even within firms.

The articles most closely related to our study are the papers by Daly, Hobjin and Wiles, (2011) and Blundell, Reed and Stoker, (2003). Daly, Hobjin and Wiles, (2011) developed a decomposition method that analyzes how median wage growth depends on the wage growth of job stayers and worker restructuring. Their method also produces explicit expressions for the various restructuring components. The key difference with our approach is that they model median weekly earnings whereas we model a standard measure of aggregate wage growth (i.e., the hours-weighted average). Furthermore, they do not consider job restructuring, which plays a key role in our analysis.

Blundell, Reed and Stoker, (2003) used a sample selection model to decompose the logarithm of average wage to the average of log wages of individuals and three bias terms. The first term reflects the bias arising from taking expectations of logarithmic variables and is related to wage dispersion. The second term captures changes in worker composition, and the third term captures the bias from the heterogeneity in hours worked. An important substantive difference to our work is that they did not consider job restructuring. The methodological approaches are also quite different.

\section{Micro-Level Mechanisms and Their Measurement}

The basic idea in the decomposition is to decompose aggregate wage growth into the wage growth of job stayers $(J S)$ and job and worker restructuring, i.e., 
$\Delta W_{t}=\Delta W_{J S}+$ Job restructuring + Worker restructuring. In our terminology, a unit refers to an occupation group in a firm, a job refers to an employment position in a unit that is filled by a worker, and a job stayer is an employee who stays in the same unit for two consecutive time periods.

The decomposition is performed in two steps: first at the level of units $(i)$ and then at the level of workers $(j)$ for the continuing units. In the first step, $\Delta W_{t}$ is decomposed into wage growth within units $\left(W H_{i}\right)$ and job restructuring, which is represented by 1) the changing input (hours worked) shares between $\left(B_{i}\right)$ the continuing units; 2) the entry $\left(N_{i}\right)$ of units; and 3) the exit $\left(X_{i}\right)$ of units. Moreover, the decomposition includes four cross terms $\left(C_{i}\right)$ such that there is one for each of the four components described above. These cross terms make the sum of the decomposition equal to the standard aggregate measure of wage growth. Importantly, they permit a useful interpretation of the main components of interest. In symbolic terms, the first step is

$$
\Delta W_{t}=W H_{i}+B_{i}+N_{i}+X_{i}+C_{i}
$$

In the second step, which is similar to the first step, $W H_{i}$ is further decomposed into workerlevel sources as follows:

$$
W H_{i}=W H_{j}+B_{j}+N_{j}+X_{j}+C_{j} .
$$

Next, we present details of the decomposition. A numerical illustration of the method is presented in the Supplementary material available as an Online Appendix.

\subsection{Job-Worker Decomposition}

Ultimately, we are interested in the standard measure of the aggregate wage per labor input in year $t$, or $W_{t}$, which can be presented formally as follows:

$$
W_{t}=\frac{\sum_{i} \sum_{j} w_{i j t} \cdot h_{i j t}}{\sum_{i} \sum_{j} h_{i j t}},
$$

where $w_{i j t}$ is the hourly wage, and $h_{i j t}$ represents the hours worked by worker $j$ who works in unit $i$ (e.g., on a certain task in a certain firm) in year $t$. 
Our goal is to measure the growth rate of the standard aggregate wage between years $s$ and $t$. Typically, this type of measurement is performed using a log difference; however, following the example of Davis and Haltiwanger, (1992), we convert wage growth into a growth rate using the average wage as a denominator. This conversion provides us with a close approximation of the standard measure of the growth rate (e.g., the log-difference of the absolute aggregate wage levels between two consecutive years). As we aggregate normal absolute wages instead of log wages, we avoid the typical log bias, which is potentially troublesome in these types of analyses even though it is usually ignored (see Section 3.1.2. and Section 4 in the Supplementary material for a more detailed discussion).

\subsubsection{Step 1: Unit-level decomposition (for unit i)}

The aggregate wage growth rate may be decomposed into unit-level sources using the following formula:

$$
\begin{array}{ll}
\ln \frac{W_{t}}{W_{s}} \cong \frac{W_{t}-W_{s}}{\bar{W}_{t}}= & \left\{W H^{i}\right\} \\
\sum_{i \in C(i)} \bar{s}_{i t}^{C(i)} \frac{\left(w_{i t}-w_{i s}\right)}{\bar{w}_{i t}}+ & \left\{B^{i}\right\} \\
\sum_{i \in C(i)}\left(s_{i t}{ }^{C(i)}-s_{i s}{ }^{C(i)}\right) \frac{\bar{w}_{i t}}{\bar{W}_{t}^{C(i)}}+ & \left\{N^{i}\right\} \\
\sum_{i \in N(i)} s_{i t} \frac{\left(w_{i t}-\bar{W}_{t}{ }^{C(i)}\right)}{\bar{W}_{t}^{C(i)}}+ & \left\{X^{i}\right\} \\
\sum_{i \in X(i)} s_{i s} \frac{\left(\bar{W}_{s}^{C(i)}-w_{i s}\right)}{\bar{W}_{s}^{C(i)}}+ & \left\{C^{i}\right\} \\
\text { cross terms of jobs }
\end{array}
$$

where $s_{i t}=\frac{h_{i t}}{\sum_{i} h_{i t}}, s_{i s}=\frac{h_{i s}}{\sum_{i} h_{i s}}, s_{i t}{ }^{C(i)}=\frac{h_{i t}}{\sum_{i \in C(i)} h_{i t}}, \bar{s}_{i t}{ }^{C(i)}=0.5\left(s_{i s}{ }^{C(i)}+s_{i t}{ }^{C(i)}\right)$, $w_{i t}=\frac{\sum_{j} w_{i j t} \cdot h_{i j t}}{\sum_{j} h_{i j t}}, \bar{w}_{t}=0.5\left(w_{i s}+w_{i t}\right) ; W_{t}^{C(i)}=\frac{\sum_{i \in C(i)} w_{i t} \cdot h_{i t}}{\sum_{i \in C(i)} h_{i t}}$, and $\bar{W}_{t}^{C(i)}=0.5\left(W_{s}^{C(i)}+W_{t}^{C(i)}\right)$

Furthermore, $i$ refers to a unit, $j$ refers to a worker, $t$ refers to an end period, $s$ refers to an initial period (e.g., in the case of annual changes, $s=t-1), C(i)$ refers to the group of continuing units (that existed in both $t$ and $s$ ), $N(i)$ refers to the group of entering units (that 
existed in $t$ but not in $s$, and $X(i)$ refers to the group of exiting units (that existed in $s$ but not in $t$ ). Thus, $s_{i t}{ }^{C(i)}$ indicates the share of hours worked of unit $i$ among all continuing units in year $t$.

The formula makes use of a Bennet, (1920) type of decomposition of the aggregate wage growth in the continuing units (see the second and third rows). This feature is important for our decomposition because the Bennet index has strong justifications from axiomatic theory, as shown by Diewert, (2005). This fact also makes our approach related to formulas used in the analysis of aggregate productivity growth (Maliranta, 2005,Böckerman and Maliranta, 2007,Diewert and Fox, 2009) and in the analysis of skill upgrading (Vainiomäki, 1999). Our formula differs from certain popular alternatives proposed in the literature with respect to the interpretation of the components, particularly the within component (Foster, Haltiwanger and Krizan, 2001,Balk, 2003,see Baily, Hulten and Campbell, 1992,Griliches and Regev, 1995). However, the formula applied in this paper is particularly suitable for our purpose because we require a measure of the wage growth of job stayers that is distinct from the effects arising from entries and exits (as for a discussion, see Melitz and Polanec, 2015,Maliranta, 2003).

The first component shown in the second row of (2) is the within component of the jobs, which indicates the weighted average of the wage growth rates of the units. By definition, it holds that $\sum_{i \in C(i)} \bar{s}_{i t}^{C(i)}=1$, which indicates that the within component represents the growth rate of an average hour worked in the continuing units. Notably, $\sum_{i \in C(i)} \bar{s}_{i t}^{C(i)} \frac{\left(w_{i t}-w_{i s}\right)}{\bar{w}_{i t}} \cong \sum_{i \in C(i)} \bar{s}_{i t}^{C(i)} \ln \frac{w_{i t}}{w_{i s}}$. In our empirical application, the absolute difference in the annual growth rates of these alternative measures is always less than 0.02 percentage points.

The third row presents the between component, which measures the contribution of changes in the composition of hours worked between the continuing units. This contribution is positive (negative) if those continuing units that have a relatively high wage level, i.e., $\frac{w_{i t}}{\bar{W}_{t}^{C(i)}}>1$, have increased (decreased) their share of hours worked among the continuing units, i.e., $s_{i t}^{C(i)}>s_{i s}^{C(i)}\left(s_{i t}^{C(i)}<s_{i s}^{C(i)}\right)$. 
The fourth row indicates the entry component of the units, and the fifth row indicates the exit component (i.e., the exit of units). The entry component is positive if the wage level of the new units is higher than the wage level of the continuing units in the year in which they appear, and this component is negative if the new units' wage level is lower than the continuing units' wage level in the year in which they appear. The magnitude of the component depends on the hour share of the new units, i.e., $\sum_{i \in N(i)} s_{i t} \leq 1$. Analogously, the exit component is positive if the wage level of the exiting units is lower than the wage level in the units that will continue in the next period and negative if this wage level is higher than the corresponding wage level in the continuing units; the magnitude depends on the hour share of the exiting units, i.e., $\sum_{i \in X(i)} s_{i s} \leq 1$. An important feature of the decomposition is that the entry and exit components are mutually symmetric and have clear interpretations. These characteristics are present because both components are based on comparisons with continuing units at a relevant point in time (i.e., the initial year for an exit and the end year for an entry).

The decomposition can be applied to either real or nominal wages. The restructuring components are practically unaffected by the choice of the deflator because they measure nominal wage levels relative to the average. As a concrete demonstration, we performed decompositions both with nominal wages and real wages (deflated with consumer prices) and found that the absolute difference in the between components is always less than 0.008 percentage points. Naturally, the difference in (i.e., growth) terms, e.g., the aggregate wage growth and the wage growth of job stayers, is affected by the choice of the deflator.

\subsubsection{The cross terms}

The components presented above are purposely derived in these forms to permit a useful interpretation. As a consequence, this decomposition also includes a set of correction components called "cross terms." The cross terms arise from the use of absolute wages and not their logs, which is typical. The cross terms provide measures of the bias (i.e., the discrepancy with the standard aggregate wage growth rate) that emerge when aggregation is performed using log wages. A more detailed analysis of the log-bias is included in the Supplementary material. 


$$
\begin{array}{ll}
\sum_{i \in C(i)} \bar{s}_{i t}^{C(i)} \frac{\left(w_{i t}-w_{i s}\right)}{\bar{w}_{i t}}\left(\frac{\bar{w}_{i t}-\bar{W}_{t}}{\bar{W}_{t}}\right)+ & \left\{C W H^{i}\right\} \\
\sum_{i \in C(i)}\left(s_{i t}{ }^{C(i)}-s_{i s}{ }^{C(i)}\right) \frac{\bar{w}_{i t}}{\bar{W}_{t}^{C(i)}}\left(\frac{\bar{W}_{t}{ }^{C(i)}-\bar{W}_{t}}{\bar{W}_{t}}\right)+ & \left\{C B^{i}\right\} \\
\sum_{i \in N(i)} s_{i t} \frac{\left(w_{i t}-\bar{W}_{t}{ }^{C(i)}\right)}{\bar{W}_{t}^{C(i)}}\left(\frac{\bar{W}_{t}^{C(i)}-\bar{W}_{t}}{\bar{W}_{t}}\right)+ & \left\{C N^{i}\right\} \\
\sum_{i \in X(i)} s_{i s} \frac{\left(\bar{W}_{s}{ }^{C(i)}-w_{i s}\right.}{\bar{W}_{s}^{C(i)}}\left(\frac{\bar{W}_{s}^{C(i)}-\bar{W}_{t}}{\bar{W}_{t}}\right) & \left\{C X^{i}\right\}
\end{array}
$$

In addition to making all components add up closely to the standard aggregate measure of the wage growth rate, these components also have economic interpretations. In particular, the first component in the second row of Equation (3) is associated with the within component (referred to as the cross term of the within component of the units and denoted by $C W H_{i}$ ). If units with relatively low wage levels have a tendency to have higher wage growth rates (i.e., if there is a type of " $\beta$-convergence" [Barro and Sala-i-Martin, (1992)] in the wage levels among continuing units), then the cross term of the within component is negative. The reason for this is that if two units are of identical size and have identical wage growth rates, a unit that has a lower wage level makes a smaller contribution to the standard aggregate wage growth. In other words, if low-wage units have higher wage growth rates, then the within component, which is measured by the weighted average growth rate of the units, overstates the contribution of the wage growth of the units to the standard aggregate wage growth.

\subsubsection{Step 2: Worker-level decomposition}

The within component in equation (2) is not ideal for measuring the wage growth of stayers because it indicates the average rate of the wage growth of the continuing units. An important insight derived from our decomposition is that job stayers can be found exclusively in continuing units, and the contributions of these job stayers to the wage growth of the unit can be measured identically to how the contributions of continuing units to aggregate wage growth are measured.

In this step, we apply the decomposition formula once more, but it is now applied at a lower level of aggregation for each of the continuing units. This variation allows us to split the 
within component of the units into four worker-level sources. The first of these sources is the within component of job stayers, the second is the changing input shares between job stayers within the continuing units, the third is the entry of workers (i.e., newly hired workers) into the continuing units, and the fourth is the exit of workers (i.e., the separation of workers) from the continuing units. Formally, this partition of the sources can be written as follows:

$$
\begin{array}{ll}
\sum_{i \in C(i)} \bar{s}_{i t}^{C(i)} \frac{\left(w_{i t}-w_{i s}\right)}{\bar{w}_{i t}}= & \left\{W H^{i}\right\} \\
\sum_{i \in C(i)} \bar{s}_{i t}^{C(i)} \sum_{j \in C(j)} \bar{s}_{i j t}{ }^{C(j)} \frac{\left(w_{i j t}-w_{i j s}\right)}{\bar{w}_{i j t}}+ & \left\{W H^{j}\right\} \\
\sum_{i \in C(i)} \bar{s}_{i t}^{C(i)} \sum_{j \in C(j)}\left(s_{i j t}{ }^{C(j)}-s_{i j s}{ }^{C(j)}\right) \frac{\bar{w}_{i j t}}{\bar{w}_{i t}{ }^{C(j)}}+ & \left\{B^{j}\right\} \\
\sum_{i \in C(i)} \bar{s}^{C}{ }^{C(i)} \sum_{j \in N(j)} s_{i j t} \frac{\left(w_{i j t}-w_{i t}{ }^{C(j)}\right)}{w_{i t}{ }^{C(j)}}+ & \left\{N^{j}\right\} \\
\sum_{i \in C(i)} \bar{s}^{C}{ }^{C(i)} \sum_{j \in X(j)} s_{i j t} \frac{\left(w_{i s}{ }^{C(j)}-w_{i j s}\right)}{w_{i s}{ }^{C(j)}}+ & \left\{X^{j}\right\} \\
\text { cross terms of workers } & \left\{C^{j}\right\}
\end{array}
$$

where $s_{i j t}{ }^{C(j)}=\frac{h_{i j t}}{\sum_{j \in C(j)} h_{i j t}}, \bar{s}_{i j t}{ }^{C(j)}=0.5\left(s_{i j s}{ }^{C(j)}+s_{i j t}{ }^{C(j)}\right), \bar{w}_{i j t}=0.5\left(w_{i j s}+w_{i j t}\right)$, $w_{i t}{ }^{C(j)}=\frac{\sum_{j \in C(j)} w_{i j t} \cdot h_{i j t}}{\sum_{j \in C(j)} h_{i j t}}$, and $\bar{w}_{i t}{ }^{C(j)}=0.5\left(w_{i s}{ }^{C(j)}+w_{i t}{ }^{C(j)}\right)$. In these equations, $j$ refers to a worker, $C(j)$ refers to the group of job stayers (who worked in the same occupation and firm in $t$ and $s$ ), $N(j)$ refers to the group of hired workers (who worked in the unit in $t$ but not in $s$ ), and $X(j)$ refers to the group of separated workers (who worked in the unit in $s$ but not in $t)$.

The second row of Formula (4) indicates our measure of the wage growth of the stayers, which is a weighted average of their wage growth rate in accordance with the Divisia index principle. Note that we have the important property $\sum_{i \in C(i)}{\overline{s_{i t}}}^{C(i)} \sum_{j \in C(j)}{\overline{s_{i j t}}}^{C(i)}=1$, which indicates that the within component represents the growth rate of the hourly wage earned by an average job stayer in a continuing firm. 
The third row is the between component of workers, which is positive when there is a positive relationship between the wage level and the change in hours worked among job stayers within continuing units. The fourth row is the entry component of workers, which is positive when newly hired workers have a higher wage level on average than job stayers in the unit into which they have been hired. The fifth row is the exit component of workers, which is positive when separating workers have a lower wage level on average than the job stayers in the unit from which they have separated.

Similar to the decomposition of the unit-level sources, the components that measure worker-level sources of wage growth include the following cross terms:

$$
\begin{array}{ll}
\sum_{i \in C(i)} \bar{s}_{i t}^{C(i)} \sum_{j \in C(j)} \bar{s}_{i j t}{ }^{C(i)} \frac{\left(w_{i j t}-w_{i j s}\right)}{\bar{w}_{i j t}}\left(\frac{\bar{w}_{i j t}-\bar{w}_{i t}}{\bar{w}_{i t}}\right)+ & \left\{C W H^{j}\right\} \\
\sum_{i \in C(i)} \bar{s}_{i t}^{C(i)} \sum_{j \in C(j)}\left(s_{i j t}{ }^{C(i)}-s_{i j s}{ }^{C(i)}\right) \frac{\bar{w}_{i j t}}{\bar{w}_{i t}{ }^{C(j)}\left(\frac{\bar{w}_{i t}{ }^{C(j)}-\bar{w}_{i t}}{\bar{w}_{i t}}\right)+} & \left\{C B^{j}\right\} \\
\sum_{i \in C(i)} \bar{s}_{i t}^{C(i)} \sum_{j \in N(j)} s_{i j t} \frac{\left(w_{i j t}-w_{i t}{ }^{C(j)}\right)}{w_{i t}{ }^{C(j)}}\left(\frac{w_{i t}{ }^{C(j)}-\bar{w}_{i t}}{\bar{w}_{i t}}\right)+ & \left\{C N^{j}\right\} \\
\sum_{i \in C(i)} \bar{s}_{i t}{ }^{C(i)} \sum_{j \in X(j)} s_{i j t} \frac{\left(w_{i s}{ }^{C(j)}-w_{i j s}\right)}{w_{i s}{ }^{C(j)}}\left(\frac{w_{i s}{ }^{C(j)}-\bar{w}_{i t}}{\bar{w}_{i t}}\right) & \left\{C X^{j}\right\}
\end{array}
$$

Equations (2)-(5) together give a decomposition of the standard aggregate wage growth rate that includes separate components for job and worker restructuring.

\section{Data}

We use wage data from the Confederation of Finnish Industries (EK), , which is the central organization of employer associations. The main industries covered by the data are manufacturing, construction, energy, and transportation ${ }^{2}$. The member firms of the EK employ the majority of employees in the manufacturing sector. The wage data are based on an annual survey of employers; with the exception of the smallest firms, a response from member firms is mandatory. The data cover the years 1985-2010. Wage data are used in

\footnotetext{
${ }^{2}$ Table A1 in the Supplementary material given in the Online Appendix show the detailed industry
} composition. 
collective bargaining and form the basis for the private sector wage structure data maintained by Statistics Finland, which is the country's statistical authority. Thus, the information that we use comes from the wage records of firms and is highly reliable. We concentrate on the manufacturing sector. On average, the data contain approximately 250,000 individuals and 1,100 firms annually.

The data include detailed information on wages, job titles, and unique person and firm identifiers and form a linked employer-employee panel that allows people to be followed over time, possibly as they work for different firms. Thus, these data contain all of the necessary information to implement our methods.

Wage variables differ for blue-collar and white-collar employees. For blue-collar employees, the data include three separate measures of hourly wages (fixed hourly wages, reward rates, and piece rates) and the hours worked during the quarter of the year of the survey. The figures for earnings include overtime pay and various wage supplements (e.g., Sunday compensation) but exclude bonuses. Hourly earnings are calculated as wages divided by hours worked. For white-collar employees, hourly earnings are calculated as the monthly earnings (inclusive of the base salary and some minor wage supplements) divided by the contract hours; bonuses are excluded from these figures as well.

The job titles for white-collar employees are uniform throughout the various industries. Prior to 2002, there were 75 job titles in use. There are now 56 titles in use due to reforms in job titles that occurred in 2002. As a result, 2002 is omitted from all analyses in which job titles are required. For blue-collar workers, job titles are often specific to an industry and there are 141 titles in the data throughout the entire period of observation. The average number of job titles for white-collar and blue-collar employees in a given firm weighted by the hours worked in the firm (the corresponding unweighted numbers are in parentheses) from 1995-2010 is 40 (17) and 6 (4), respectively.

Because the data source does not cover the entire manufacturing sector (as not all firms are members of the EK), we assessed the representativeness of these data by comparing the aggregate wage series to figures from another data set. Comparisons of EK data with the official index of wage and salary earnings (from Statistics Finland) that is presented in Figure 1 indicate that our data give a representative picture of the standard aggregate wage growth in the manufacturing sector. The similarity of these two series is noteworthy for two reasons. 
First, because the growth rate of wages measured with EK data refers to average wages, these figures include the effect of restructuring, whereas the index of wage earnings attempts to eliminate the effect of restructuring ${ }^{3}$. Second, the data underlying the index of wage and salary earnings are somewhat more comprehensive because they include other data sources (e.g., for smaller firms) in addition to EK data.

[Insert Figure 1 about here]

\section{Results}

\subsection{Micro-Components of Aggregate Wage Growth}

Table 1 presents the average annual nominal aggregate wage growth rate and its components separately for the years 1985-1995 and1995-2010. The first period concerns years of rapid wage growth, enabled by high productivity growth of a catching-up country and high inflation, enabled by own currency. In the latter period wage growth was substantially lower (see also Figure 1). A more detailed decomposition is given in the Supplementary material in Table A4. Five main findings presented in this table are notable. First, the aggregate wage growth rate is lower than the wage growth rate of job stayers (3.91\% vs. $4.17 \%$ during the period $1995-2010)$. Thus, the sum of the job- and workerrestructuring effects is negative (-0.26 during 1995-2010). Second, job restructuring has an important effect on aggregate wage growth $(0.55 \%$ in the years $1995-2010$, excluding the effect of the cross terms). This result is mainly due to the between component of the unitshigh-wage units have increased their share of hours worked. The entry of new units has a small negative effect, implying that entering units have had wages that were below average. The exit effect is positive, which means that exiting units have been predominantly low-wage units. These findings have parallels in the productivity literature that shows the importance of reallocations of resources for productivity growth (see e.g. Foster, Haltiwanger and Krizan, 2001).

Third, worker restructuring within units has a significant negative effect as a result of the large negative impact of worker entries, which indicates that newly hired workers typically

\footnotetext{
${ }^{3}$ The index of wage earnings uses fixed weights based on the following classifications: sector, industry, salaried employees, hourly paid employees, and statistical source. Thus, changes in the relative sizes of the classes formed by these variables do not affect the index.
} 
earn less than job stayers in the unit. However, the exit effect of workers is positive, which indicates that separating workers currently earn less than the job stayers of a unit on average. However, the net entry effect (the sum of the entry and exit effects) is clearly negative ($0.75 \%$ in the years 1995-2010). Fourth, the cross terms have only a small effect on the aggregate wage growth. Fifth, the basic patterns in the components are similar over the periods 1995-2010 and 1985-1995.

[Insert Table 1 around here]

\subsection{Cyclicality of the Components}

The numbers shown in Table 1 hide the temporal patterns of the components. To study the cyclicality of the components, we follow the econometric approach taken in the literature on wage flexibility as closely as possible.

The most common approach taken in the literature is a two-stage estimation approach (Solon, Barsky and Parker, 1994,Solon, Whatley and Stevens, 1997,Shin and Solon, 2007,Devereux, 2001,Devereux and Hart, 2006,Pissarides, 2009, Haefke, Sonntag and van Rens, 2013,Kudlyak, 2014). In the first stage, individual data is used to estimate average annual change in log real hourly earnings. This estimate is obtained from time dummies in a linear regression model. In the second stage, the time series formed by these time dummies is regressed on a constant, time trend and a business cycle indicator. The national unemployment rate is a typical indicator of the business cycle, but labor productivity has become popular in more recent macroeconomic literature (e.g.Pissarides, 2009,Haefke, Sonntag and van Rens, 2013). GDP growth is also used in the literature (e.g. Solon, Whatley and Stevens, 1997).

In our application, the decomposition corresponds to the first stage described above. In the second stage, we regress each of the 12 components in Table 1 on constant, time trend and a business cycle indicators. Following the literature, we use national unemployment rate, labor productivity in manufacturing and GDP growth as business cycle indicators. In the regressions, the aggregate wage growth and the wage growth of the job stayers are deflated by the consumer price index. The restructuring components are unaffected by deflation, as explained in section 3.1.1. 
The coefficients of business cycle indicators and their statistical significance levels are reported in Table 2. By construction, the coefficients are mutually related based on the jobworker decomposition (presented in Equations (2)-(5)), which is shown in Table 1.

[Insert Table 2 around here]

The first part of the table reports the results obtained using the first difference of the unemployment rate. This illustrates a number of important findings. First, there is a negative relationship between the standard aggregate wage growth and the unemployment rate (the coefficient is -0.47), which indicates that there is some procyclical flexibility in aggregate wages.

Second, the coefficient of the within component is highly statistically significant and substantially larger in absolute value compared to the aggregate wage growth, which indicates procyclical flexibility in the wages of the job stayers. The coefficient implies that a one percentage point increase in the unemployment rate decreases the wage growth of the job stayers by 0.7 percentage points. Comparing this result to the result on aggregate wages shows that aggregate wages are smoothed by job and worker restructuring. The finding that the wages of job stayers are more procyclical than aggregate wages is similar to the findings of Solon, Barsky and Parker, (1994) and Shin, (1994). Moreover, our finding that the wages of job stayers are almost twice as cyclically sensitive as aggregate wages is similar to the findings in these studies regarding the differences between the results using aggregate data and microdata. Indeed, our finding that the wages of job stayers are cyclically flexible is similar to the findings of Devereux and Hart, (2006). However, our results show less cyclical sensitivity than their results from the United Kingdom.

Third, in our approach the differences in the aggregate wage and job stayer wage flexibilities can be attributed to the countercyclical pattern of job and worker restructuring effects. When using the unemployment rate as a business cycle indicator, we see that worker restructuring demonstrates a strong countercyclical pattern. The sign of the coefficient of the job restructuring component indicates countercyclicality, but it is not statistically significant.

Fourth, the countercyclical pattern of the worker-restructuring effect can almost entirely be attributed to the countercyclical contributions of entrants, when business cycles are gauged by the unemployment rate. New entrants have a more negative effect on the aggregate wage level of their jobs in upturns than in downturns. There are two potential channels for this 
cyclical asymmetry. The wage gap between the hired workers and the job stayers may be larger (in favor of job stayers), or the employment share of the hired workers may be larger during upturns than it is during downturns.

Fifth, when business cycle fluctuations are measured by labor productivity, we see that the countercyclical pattern of restructuring effect can mostly be attributed to that of job restructuring. In other words, our approach shows that different business cycle indicators are related to aggregate wage dynamics through different restructuring mechanisms; unemployment operates through worker restructuring and productivity growth through the job restructuring effect. It is also seen that the cyclicality of job restructuring is driven by the between-component. One interpretation of this finding is that the share of low-productivity jobs decreases during downturns. Since these jobs typically also pay low wages, job restructuring increases aggregate wages during recessions. Sixth, when the growth rate of GDP is used as an indicator of business cycles, the results show that the aggregate wages are acyclical, the wages of job stayers are procyclical, and both restructuring components are countercyclical.

To complement the regression analysis, Figure 2 shows the effect of job restructuring (in this paper, the sum of the between, entry, and exit components) over time. To interpret the business cycle, the figure displays the change in the hours worked in manufacturing that is measured in the national accounts. Because it is presented on a reversed scale, the close comovement of the two series indicates a strong countercyclicality in the effect of job restructuring. The figure shows that job restructuring has an important role in the growth of aggregate wages. The effect is typically positive but varies over the business cycle. The effect of job restructuring has a countercyclical pattern; it is highest during recessions (in 19901991, 2001, and 2008-2009) and the most negative in sharp upturns (1994).

[Insert Figure 2 around here]

Figure 3 shows that the effect of worker restructuring is also countercyclical, implying that worker restructuring smooths aggregate wage changes. This result corroborates earlier findings in the literature, but we also considered the distinct role of job restructuring. More specifically, our results show that worker restructuring has a strong countercyclical effect on wages within jobs.

[Insert Figure 3 around here] 


\subsection{The Quality of Labor Input and Job Restructuring}

The growth-accounting literature provides a method to compute how labor quality has contributed to economic growth (e.g. Ho and Jorgenson, 1999). The idea is to compute a volume index of labor input that takes into account the quality of hours worked, i.e., to construct a quality-adjusted measure of labor input. The measurement is based on a crossclassification of hours worked that is formed using worker characteristics (usually gender, age, education, and self-employment status). The index is measured by computing a weighted average of the changes of hours worked by the groups. The weight of each group in each period is given by the average share of compensation so that changes in high-wage hours are given a greater weight than low-wage hours. As a result, changes in the compositional structure toward high-wage employment groups have a positive effect on the quality-adjusted labor input index. Growth in labor quality is defined as the difference between the growth of the quality-adjusted labor input and the growth in a quality-unadjusted raw measure of hours worked.

The approach of our decomposition method is not to examine the quality-adjusted changes in the volume of labor input but the price of hours worked, i.e., wage growth. Our decomposition includes a component for measuring the contribution of the compositional changes in jobs (i.e., job restructuring) to the change in the average wage. As such, it provides an indicator of the change in the average job quality. Because the structure of job characteristics (occupational structure, in particular) is closely linked to the structure of employment characteristics (educational and wage structures, in particular), we might expect that the changes in labor quality measured by the growth -accounting methodology will be closely related to the changes in job quality measured by our wage decomposition.

Figure 4 confirms this hypothesis, especially after 1995. The figure shows a striking similarity to the job restructuring component in terms of both short-run variations and longrun trends, which is remarkable given that the two alternative measures of labor input or quality growth are based on different approaches (our wage decomposition vs. traditional growth accounting) and different data (EK data vs. the register and survey data underlying the National Accounts). Therefore, an empirical comparison with the job restructuring 
component of aggregate wage growth reveals a close link to the growth accounting literature that examines the contribution of labor quality growth to aggregate productivity growth. However, as our indicator includes three distinct subcomponents that measure job restructuring (entry, exit, and between components), it augments the interpretation of the underlying dynamics.

[Insert Figure 4 around here]

\section{Conclusion}

Aggregate wage growth and its cyclicality depend on job and worker restructuring. The previous literature on aggregate wage dynamics has considered the role of the latter factor but ignored the former. We propose an approach that decomposes aggregate wage growth to its micro-level components and shows the contributions of job stayers, job restructuring, and worker restructuring. This method produces explicit expressions with clear interpretations for both job and worker restructuring components.

We show that both job and worker restructuring matter for aggregate wage growth. The importance of restructuring is demonstrated seen in the result that aggregate wage growth is slower than the wage growth of job stayers. This difference would be zero if there were no job and worker restructuring. We also show that these two types of restructuring have contrary implications for aggregate wage growth. Job restructuring increases aggregate wage growth mainly because existing high-wage units increase their relative employment share. Worker restructuring, on the other hand, tends to decrease aggregate wage growth. This effect is mainly the result of the entries of new workers- the effect of the exits is smaller.

Our approach provides novel insights into the macroeconomic literature considering the cyclicality of wages at the macro level by use of different indicators of business fluctuations. Our empirical analysis shows that both job and worker restructuring play a role in the cyclicality of aggregate wages, but that their importance depends on whether business cycles are measured by unemployment, labor productivity growth, or GDP growth; worker restructuring stands out when unemployment is used, job restructuring with labor productivity growth is used and both when GDP growth is used. However, irrespective of the business cycle indicator, the wages of job stayers exhibit significantly more procyclical patterns than aggregate wages. 
ONLINE APPENDIX - Supplementary materials

1. Table A1 - Industry composition

2. Numerical Illustration of the Decomposition

3. Institutional Setting

4. Patterns of Log-Bias of Aggregation

5. Table 1-Full Version 


\section{References}

Acemoglu, D., U. Akcigit, N. Bloom, and W.R. Kerr, "Innovation, Reallocation and Growth," National Bureau of Economic Research, Inc, NBER Working Papers: 18993, 2013.

Aghion, P., U. Akcigit, and P. Howitt. "Chapter 1 - What Do We Learn from Schumpeterian Growth Theory?," in P. Aghion and S.N. Durlauf (eds.), Handbook of Economic Growth, 515-563, Elsevier, 2014.

Baily, M.N., E.J. Bartelsman, and J. Haltiwanger. "Labor Productivity: Structural Change and Cyclical Dynamics," Review of Economics and Statistics, 83, 420-433, 2001.

Baily, M.N., C. Hulten, and D. Campbell. "Productivity Dynamics in Manufacturing Plants," Brookings Papers on Economic Activity, Microeconomics 1992, 187-267, 1992.

Baldwin, R.E., and T. Okubo. "Heterogeneous Firms, Agglomeration and Economic Geography: Spatial Selection and Sorting," Journal of Economic Geography, 6, 323346, 2006.

Balk, B.M. "The Residual: On Monitoring and Benchmarking Firms, Industries, and Economies with Respect to Productivity," Journal of Productivity Analysis, 20, 5-47, 2003.

Barlevy, G. "Why Are the Wages of Job Changers So Procyclical?," Journal of Labor Economics, 19, 837-878, 2001.

Barro, R.J., and X. Sala-i-Martin. "Convergence," Journal of Political Economy, 100, 223$251,1992$.

Bartelsman, E.J., and M. Doms. "Understanding Productivity: Lessons from Longitudinal Microdata," Journal of Economic Literature, 38, 569-594, 2000.

Bennet, T.L. "The Theory of Measurement of Changes in Cost of Living," Journal of the Royal Statistical Society, Series (B), 83, 455-462, 1920.

Bils, M.J. "Real Wages over the Business Cycle: Evidence from Panel Data," Journal of Political Economy, 93, 666-689, 1985.

Blundell, R., H. Reed, and T.M. Stoker. "Interpreting Aggregate Wage Growth: The Role of Labor Market Participation," American Economic Review, 93, 1114-1131, 2003.

Böckerman, P., and M. Maliranta. "The Micro-Level Dynamics of Regional Productivity Growth: The Source of Divergence in Finland," Regional Science and Urban Economics, 37, 165-182, 2007.

Carneiro, A., P. Guimares, and P. Portugal. "Real Wages and the Business Cycle: Accounting for Worker, Firm, and Job Heterogeneity," American Economic Journal:

Macroeconomics, 4, 133-152, 2012.

Daly, M.C., B. Hobjin, and T.S. Wiles. "Aggregate Real Wages: Macro Fluctuations and Micro Drivers," in Federal Reserve Bank of San Francisco, 2011.

Davis, S.J., and J.C. Haltiwanger. "Gross Job Creation, Gross Job Destruction, and Employment Reallocation," Quarterly Journal of Economics, 107 3, 819-863, 1992.

Devereux, P.J. "The Cyclicality of Real Wages within Employer-Employee Matches," Industrial \& Labor Relations Review, 54, 835-850, 2001.

Devereux, P.J., and R.A. Hart. "Real Wage Cyclicality of Job Stayers, within-Company Job Movers, and between-Company Job Movers," Industrial and Labor Relations Review, 60, 105-119, 2006.

Diewert, W.E. "Index Number Theory Using Differences Rather Than Ratios," American Journal of Economics and Sociology, 64, 347-395, 2005. 
Diewert, W.E., and K.J. Fox. "On Measuring the Contribution of Entering and Exiting Firms to Aggregate Productivity Growth," in W.E. Diewert, B.M. Balk, D. Fixler, K.J. Fox and A. Nakamura (eds.), Index Number Theory and the Measurement of Prices and Productivity, Trafford Publishing, Victoria, 2009.

Foster, L., J. Haltiwanger, and C.J. Krizan. "Aggregate Productivity Growth: Lessons from Microeconomic Evidence," in C.R. Hulten, E.R. Dean and M.J. Harper (eds.), New Developments in Productivity Analysis, 303-363, University of Chicago Press, Chicago and London, 2001.

---. "Market Selection, Reallocation, and Restructuring in the U.S. Retail Trade Sector in the 1990s," Review of Economics and Statistics, 88, 748-758, 2006.

Foster, L., J. Haltiwanger, and C. Syverson. "Reallocation, Firm Turnover, and Efficiency: Selection on Productivity or Profitability?," American Economic Review, 98, 394-425, 2008.

Gertler, M., and A. Trigari. "Unemployment Fluctuations with Staggered Nash Wage Bargaining," Journal of Political Economy, 117, 38-86, 2009.

Griliches, Z., and H. Regev. "Firm Productivity in Israeli Industry: 1979-1988," Journal of Econometrics, 65, 175-203, 1995.

Haefke, C., M. Sonntag, and T. van Rens. "Wage Rigidity and Job Creation," Journal of Monetary Economics, 60, 887-899, 2013.

Helpman, E. "Trade, Fdi, and the Organization of Firms," Journal of Economic Literature, 44, 589-630, 2006.

Helpman, E., M.J. Melitz, and S.R. Yeaple. "Export Versus Fdi with Heterogenous Firms.," American Economic Review, 94, 300-316, 2004.

Ho, M.S., and D.W. Jorgenson, "The Quality of the Us Workforce, 1948-95," Harvard University, 1999.

Klette, T.J., and S. Kortum. "Innovating Firms and Aggregate Innovation," Journal of Political Economy, 112, 986-1018, 2004.

Kudlyak, M. "The Cyclicality of the User Cost of Labor," Journal of Monetary Economics, 68, 53-67, 2014.

Lentz, R., and D.T. Mortensen. "An Empirical Model of Growth through Product Innovation," Econometrica, 76, 1317-1373, 2008.

Maliranta, M. Micro Level Dynamics of Productivity Growth. An Empirical Analysis of the Great Leap in Finnish Manufacturing Productivity in 1975-2000, Taloustieto Oy, Helsinki, 2003.

---. "R\&D, International Trade and Creative Destruction - Empirical Findings from Finnish Manufacturing Industries," Journal of Industry, Competition and Trade, 5, 27-58, 2005.

Martins, P.S., G. Solon, and J.P. Thomas. "Measuring What Employers Do About Entry Wages over the Business Cycle: A New Approach," American Economic Journal: Macroeconomics, 4, 36-55, 2012.

Melitz, M.J. "The Impact of Trade on Intra-Industry Reallocations and Aggregate Industry Productivity," Econometrica, 71, 1695-1725, 2003.

Melitz, M.J., and S. Polanec. "Dynamic Olley-Pakes Productivity Decomposition with Entry and Exit," RAND Journal of Economics, 46, 362-375, 2015.

Pissarides, C.A. "The Unemployment Volatility Puzzle: Is Wage Stickiness the Answer?," Econometrica, 77, 1339-1369, 2009.

Shin, D. "Cyclicality of Real Wages among Young Men," Economics Letters, 46, 137-142, 1994.

Shin, D., and G. Solon. "New Evidence on Real Wage Cyclicality within EmployerEmployee Matches," Scottish Journal of Political Economy, 54, 648-660, 2007. 
Solon, G., R. Barsky, and J.A. Parker. "Measuring the Cyclicality of Real Wages: How Important Is Composition Bias," The Quarterly Journal of Economics, 109, 1-25, 1994.

Solon, G., W. Whatley, and A.H. Stevens. "Wage Changes and Intrafirm Job Mobility over the Business Cycle: Two Case Studies," Industrial \& Labor Relations Review, 50, 402-415, 1997.

Statistics Finland, Index of Wage and Salary Earnings. (http://www.stat.fi/til/ati/index_en.html)

Syverson, C. "What Determines Productivity?," Journal of Economic Literature, 49, 326365, 2011.

the Confederation of Finnish Industries (EK), Wage Statistics.

Vainiomäki, J. "Technology and Skill Upgrading: Results from Linked Worker-Plant Data for Finnish Manufacturing," in J. Haltiwanger, J. Lane, J.R. Spletzer, J.J.M. Theuwes and K.R. Troske (eds.), The Creation and Analysis of Employer-Employee Matched Data, 115-145, Elsevier Science, North-Holland, Amsterdam; New York and Oxford, 1999. 


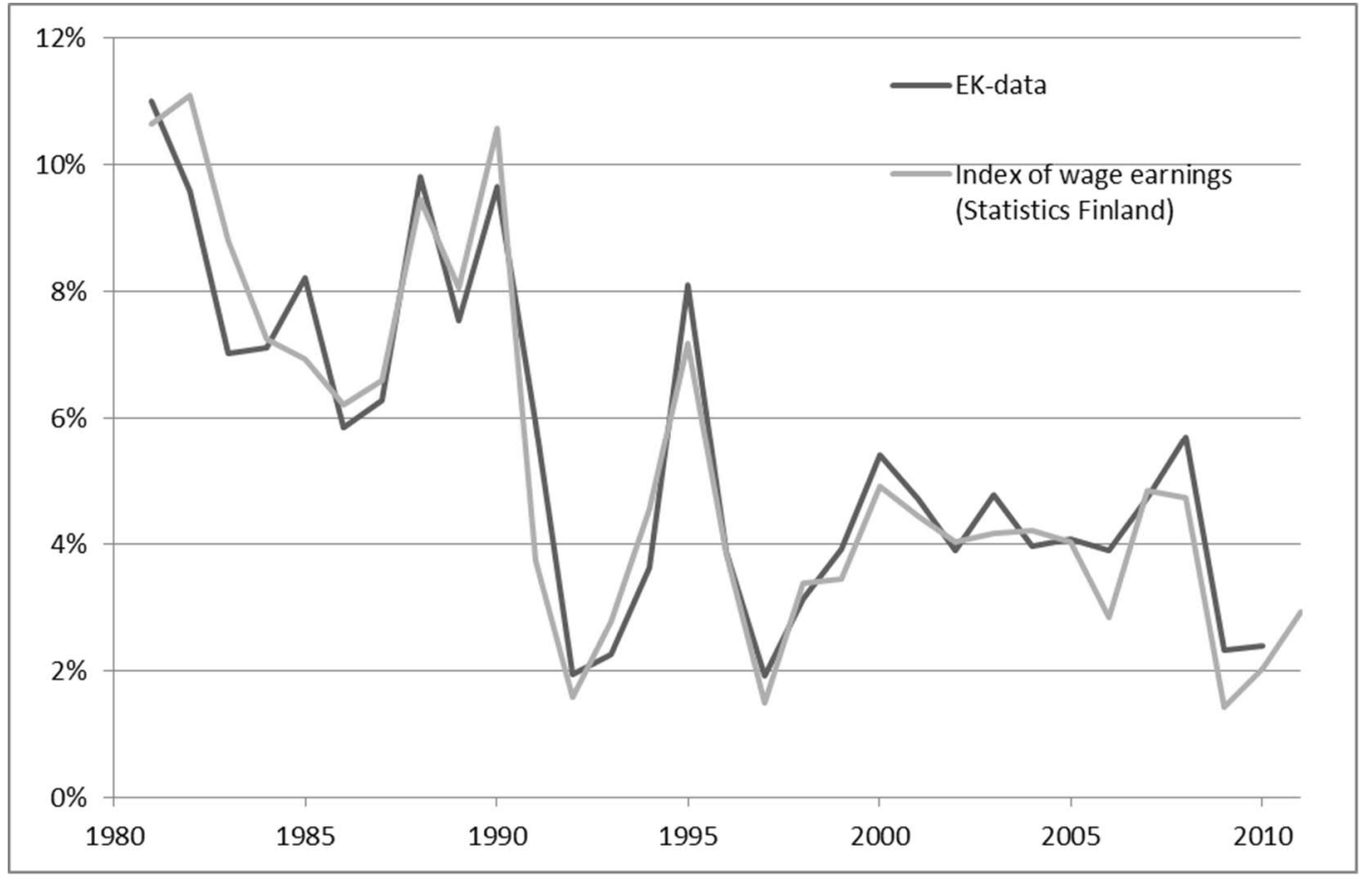

Figure 1. Nominal wage growth in manufacturing 
Table 1. Components of aggregate wage growth by job-worker decomposition: annual averages and percentage points

\begin{tabular}{|c|c|c|c|c|c|c|c|}
\hline \multicolumn{4}{|c|}{$1995-2010$} & \multicolumn{4}{|c|}{ 1985-1995 } \\
\hline Aggregate & $\begin{array}{l}\text { WH (within } \\
\text { job stayers) }\end{array}$ & $\begin{array}{l}\text { Job } \\
\text { restructuring }\end{array}$ & $\begin{array}{c}\text { Worker } \\
\text { restructuring }\end{array}$ & Aggregate & $\begin{array}{c}\text { Within } \\
\text { (job stayers) }\end{array}$ & $\begin{array}{l}\text { Job } \\
\text { restructuring }\end{array}$ & $\begin{array}{c}\text { Worker } \\
\text { restructuring }\end{array}$ \\
\hline 3.91 & 4.17 & 0.55 & -0.82 & 6.09 & 6.27 & 0.29 & -0.47 \\
\hline \multicolumn{8}{|c|}{ Restructuring components } \\
\hline & between $(B)$ & 0.46 & -0.02 & & & 0.35 & -0.01 \\
\hline & entry (N) & -0.02 & -1.02 & & & -0.14 & -0.84 \\
\hline & exit $(X)$ & 0.12 & 0.27 & & & 0.14 & 0.40 \\
\hline & cross terms (C) & -0.01 & -0.04 & & & -0.06 & -0.02 \\
\hline
\end{tabular}

Note: The year 2002 is absent because of the break in our data. 
Table 2. Regression coefficients of business cycle indicators and components based on jobworker decomposition

\begin{tabular}{|c|c|c|c|}
\hline \multicolumn{4}{|c|}{ Unemployment } \\
\hline Aggregate & $\begin{array}{c}\text { Within } \\
\text { (job stayers) }\end{array}$ & $\begin{array}{c}\text { Job } \\
\text { restructuring }\end{array}$ & $\begin{array}{c}\text { Worker } \\
\text { restructuring }\end{array}$ \\
\hline$-0.470 * *$ & $-0.702 * * *$ & 0.066 & $0.166 * * *$ \\
\hline \multicolumn{4}{|c|}{ Restructuring components } \\
\hline & between (B) & -0.023 & 0.003 \\
\hline & entry $(N)$ & -0.026 & $0.142 * * *$ \\
\hline & exit $(X)$ & 0.106 & 0.010 \\
\hline & cross-terms (C) & 0.008 & $0.011^{* * *}$ \\
\hline \multicolumn{4}{|c|}{ Labor Productivity in Manufacturing } \\
\hline Aggregate & $\begin{array}{c}\text { Within } \\
\text { (job stayers) }\end{array}$ & $\begin{array}{l}\text { Job } \\
\text { restructuring }\end{array}$ & $\begin{array}{c}\text { Worker } \\
\text { restructuring }\end{array}$ \\
\hline-0.073 & 0.021 & $-0.069 * * *$ & $-0.025^{*}$ \\
\hline \multicolumn{4}{|c|}{ Restructuring components } \\
\hline & between (B) & $-0.076 * * *$ & -0.001 \\
\hline & entry $(\mathrm{N})$ & 0.020 & -0.012 \\
\hline & exit $(X)$ & -0.011 & $-0.015^{* * *}$ \\
\hline & cross-terms (C) & -0.001 & $0.002^{* *}$ \\
\hline \multicolumn{4}{|c|}{ GDP of the economy } \\
\hline Aggregate & $\begin{array}{c}\text { Within } \\
\text { (job stayers) }\end{array}$ & $\begin{array}{c}\text { Job } \\
\text { restructuring }\end{array}$ & $\begin{array}{c}\text { Worker } \\
\text { restructuring }\end{array}$ \\
\hline 0.121 & $0.309 * * *$ & $-0.101 * *$ & $-0.087 * * *$ \\
\hline \multicolumn{4}{|c|}{ Restructuring components } \\
\hline & between $(B)$ & $-0.081^{*}$ & -0.002 \\
\hline & entry $(\mathrm{N})$ & 0.030 & $-0.066 * * *$ \\
\hline & exit (X) & -0.049 & $-0.017 * *$ \\
\hline & cross-terms (C) & -0.001 & -0.002 \\
\hline
\end{tabular}

Note: The table reports regression coefficients. Asterisks denote statistical significance $(*$ $\mathrm{p}<0.1, * * \mathrm{p}<0.05, * * * \mathrm{p}<0.01$. All of the regressions include the growth rate of consumer prices and the time trend as explanatory variables; there were 24 observations (2002 was excluded because of the break in our data). 


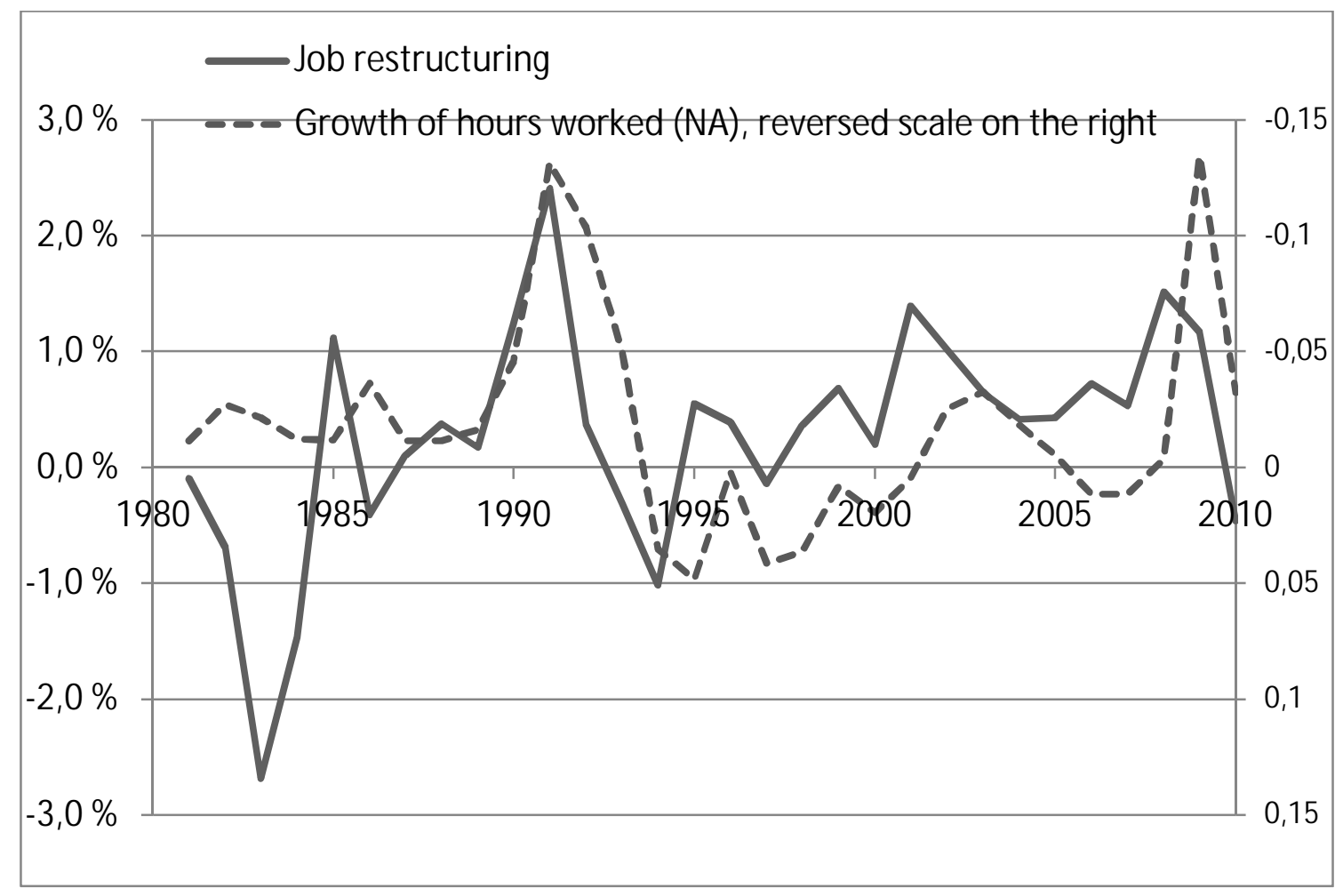

Figure 2. Job restructuring components over time.

NOTE: Figures for the growth of hours worked in the manufacturing sector were obtained from the National Accounts (NA) of Statistics Finland. The right-hand scale is reversed. The numbers for labor-input growth rates refer to the annual averages, whereas our data refer to the final quarter of the year. The job restructuring effect in the year 2002 is interpolated because of the break in the time series. 


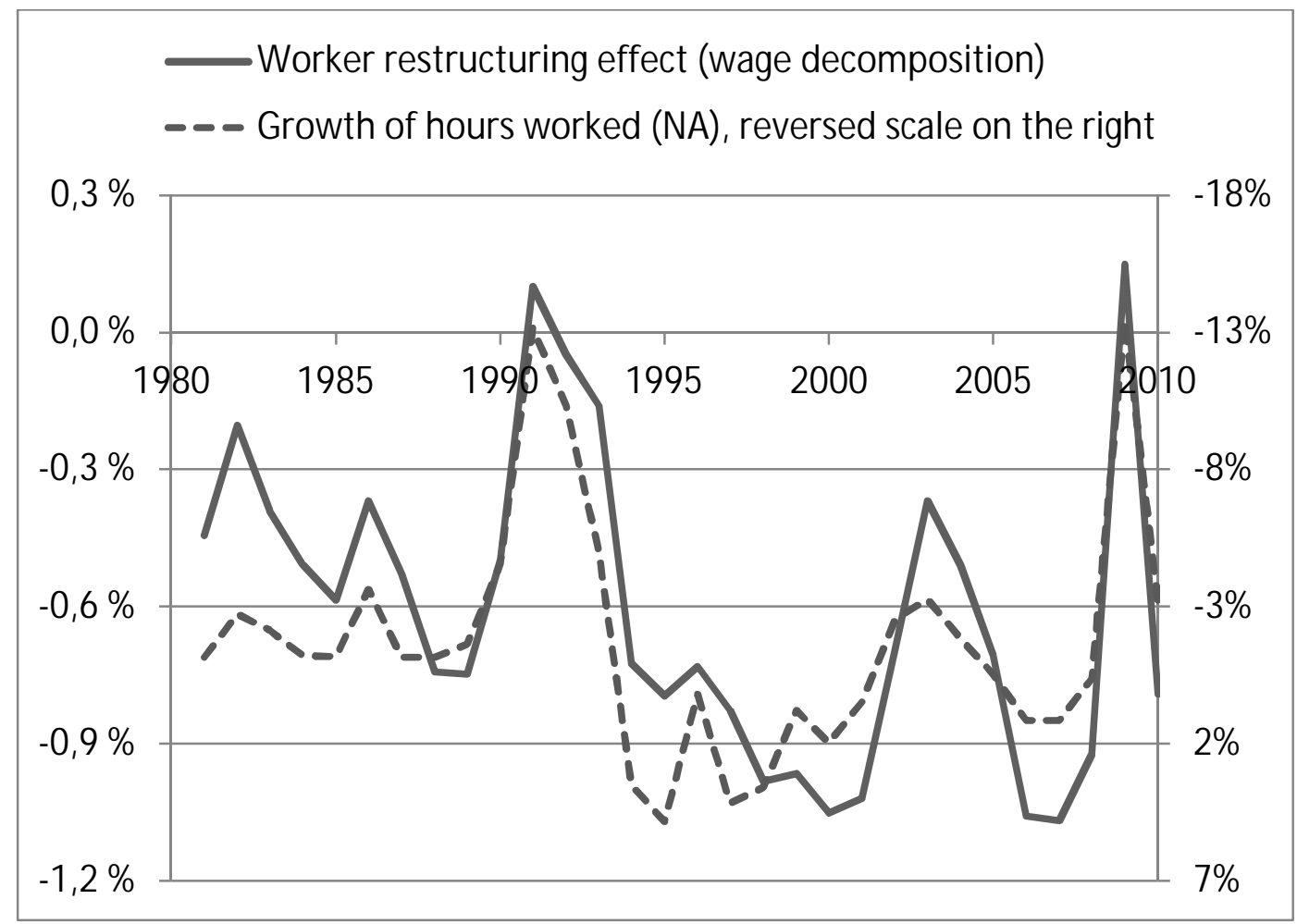

Figure 3. Patterns in the effect of worker restructuring measured by job-worker decomposition in percentage points.

NOTE: Figures for the growth of hours worked in the manufacturing sector were obtained from the National Accounts (NA) of Statistics Finland. The right-hand scale is reversed. The numbers for labor-input growth rates refer to the annual averages, whereas our data refer to the final quarter of the year. The worker restructuring effect in the year 2002 is interpolated because of the break in the time series. 


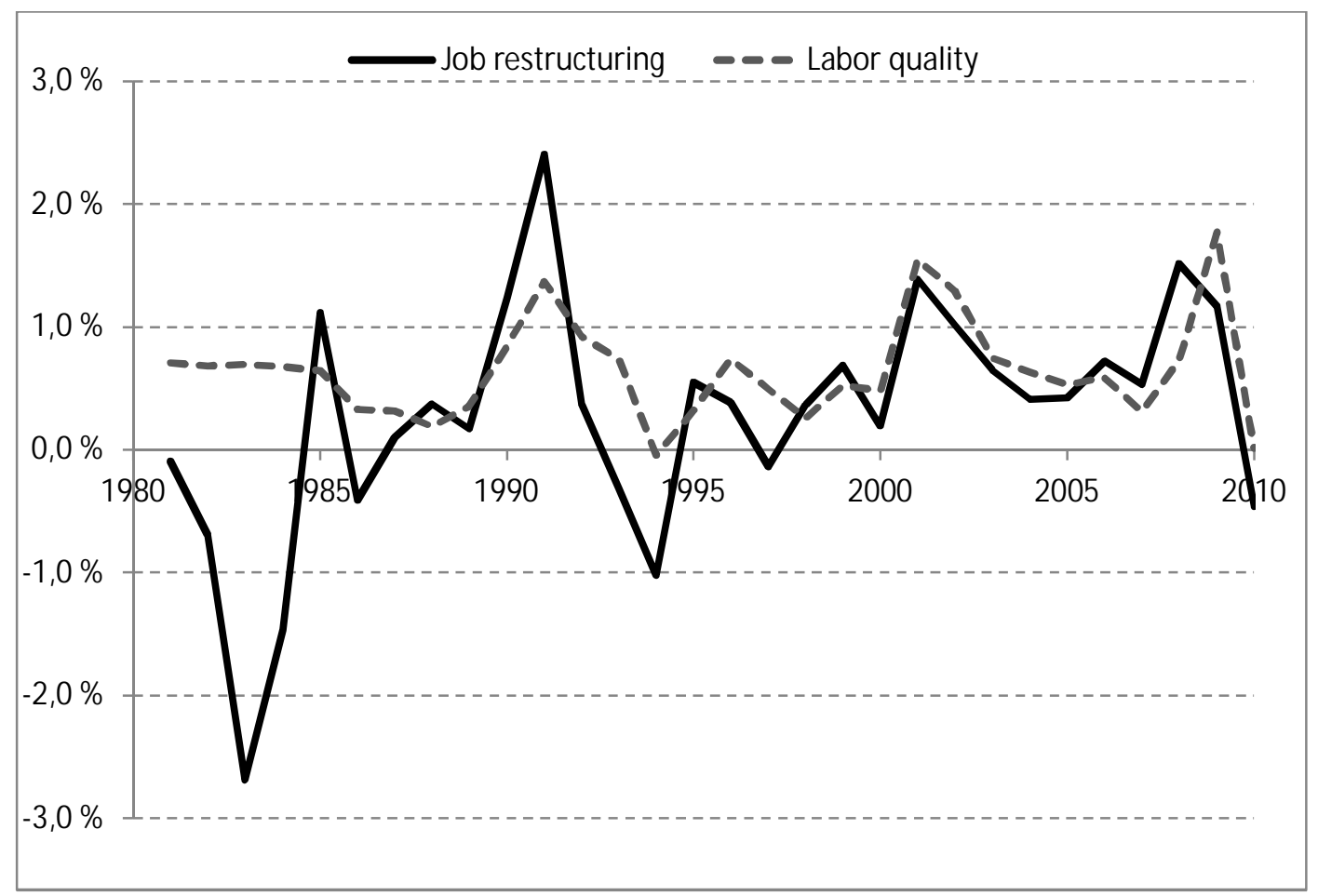

Figure 4. The wage effect of job restructuring and the labor quality effect.

NOTE: Notes: Annual figures for labor quality estimates in the manufacturing sector are obtained from Statistics Finland. Computations are based on the cross-tabulations of labor input into 18 groups (by age, education and gender). The job restructuring effect in the year 2002 is interpolated because of the break in the time series. 